\title{
openheart Predictors of clinical outcome following transcatheter aortic valve implantation: a prospective cohort study
}

\author{
Lauren Dautzenberg, ${ }^{1}$ Judith E M Pals (D) , ${ }^{1}$ Geert J Lefeber, ${ }^{1}$ Pieter R Stella, ${ }^{2}$ \\ Masieh Abawi, ${ }^{2,3}$ Marielle Emmelot-Vonk, ${ }^{1}$ Huiberdina L Koek ${ }^{1}$
}

\begin{abstract}
- Additional supplemental material is published online only. To view, please visit the journal online (http://dx.doi.org/10.
\end{abstract} 1136/openhrt-2021-001766).

To cite: Dautzenberg L, Pals JEM, Lefeber GJ, et al. Predictors of clinical outcome following transcatheter aortic valve implantation: a prospective cohort study. Open Heart 2021;8:e001766. doi:10.1136/ openhrt-2021-001766

Received 9 August 2021 Accepted 3 September 2021

Check for updates

(c) Author(s) (or their employer(s)) 2021. Re-use permitted under CC BY-NC. No commercial re-use. See rights and permissions. Published by BMJ.

${ }^{1}$ Department of Geriatric Medicine, University Medical Centre Utrecht, Utrecht, The Netherlands

${ }^{2}$ Department of Cardiology, University Medical Centre Utrecht, Utrecht, The Netherlands

${ }^{3}$ Department of Public Health and Primary Care, Leiden University Medical Center, Leiden, The Netherlands

Correspondence to Drs Lauren Dautzenberg; I. dautzenberg@umcutrecht.nl

\section{ABSTRACT}

Objective In recent years, transcatheter aortic valve implantation (TAVI) has become the treatment of choice for patients with symptomatic aortic valve stenosis considered to be at increased or high surgical risk. The aim of this study was to identify predictors of postoperative adverse events in older adults undergoing TAVI.

Methods A prospective observational cohort study of patients who were referred to a geriatric outpatient clinic for a geriatric assessment prior to TAVI was conducted. The outcomes were mortality and hospital readmission within 3 months of TAVI and the occurrence of major postoperative complications during hospitalisation according to the Clavien-Dindo classification. These three outcomes were also combined to a composite outcome. Univariate and multivariate logistic regression analyses were performed to identify predictors of the outcomes and composite outcome of adverse events.

Results This cohort included 490 patients who underwent TAVI (mean age $80.7 \pm 6.2$ years, $47.3 \%$ male). Within 3 months of TAVI, 19 (3.9\%) patients died and 46 (9.4\%) patients experienced a hospital readmission. A total of 177 (36.1\%) patients experienced one or more major complications according to the Clavien-Dindo classification during hospitalisation and 193 patients (39.4\%) experienced the composite outcome of adverse events. In multivariate analyses, cognitive impairment was identified as an independent predictor of major postoperative complications (OR 2.16; 95\% Cl 1.14 to 4.19 ) and the composite outcome of adverse events (OR 2.40; 95\% $\mathrm{Cl} 1.21$ to 4.79). No association was found between the other variables and the separate outcomes and composite outcome.

Conclusion Cognitive impairment is associated with postoperative adverse events in older patients undergoing TAVI. Therefore, it is important to screen for cognitive impairment prior to TAVI and it is recommended to include this in current TAVI guidelines.

\section{INTRODUCTION}

Stenosis of the aortic valve is one of the most common cardiovascular diseases in the Western population. ${ }^{1}{ }^{2}$ It is associated with ageing and affects one in eight individuals aged 75 years and above. ${ }^{1-3}$ In recent years, transcatheter aortic valve implantation

\section{Key messages}

What is already known about this subject?

- Stenosis of the aortic valve is one of the most common cardiovascular diseases in the Western population and associated with ageing.

- Common surgical risk scores to predict the risk of adverse events, such as the European System for Cardiac Operative Risk Evaluation and Society of Thoracic Surgeons score, do not include relevant risk factors that are specifically prevalent in the geriatric population.

- Previous studies on predictors of adverse outcomes in older patients undergoing transcatheter aortic valve implantation (TAVI) mainly focus on the occurrence of long-term mortality.

- There is a paucity of information about predictors of both (short-term) mortality and morbidity in these patients.

What does this study add?

- In this prospective cohort study on adverse outcomes in older patients, all patients underwent a Comprehensive Geriatric Assessment prior to TAVI and were given advice for appropriate treatment to prevent/reduce postoperative adverse outcomes. Cognitive impairment was found to be associated with postoperative morbidity and mortality. No association was found between other variables, like frailty, and the occurrence of adverse events.

How might this impact on clinical practice?

- Screening for cognitive impairment with a screening tool like the Mini-Mental State Examination or Montreal Cognitive Assessment could help identify patients who are at increased risk of adverse events following TAVI. Therefore, it is recommended to include screening for cognitive impairment in current TAVI guidelines.

(TAVI) has become the treatment of choice for patients with symptomatic aortic valve stenosis, considered to be at increased or high surgical risk. ${ }^{1-3}$ Common surgical risk scores, such as the European System for Cardiac Operative Risk Evaluation (EuroSCORE) and Society of Thoracic Surgeons score, are 
widely used to guide treatment options based on the predicted risk of poor outcomes. ${ }^{3}$ These models were created and validated in a standard surgical risk population. ${ }^{34}$ Therefore, these models do not include relevant risk factors that are specifically prevalent in the geriatric population. ${ }^{1-3}$ In recent years, the evidence has grown that frailty can help identify patients who are at increased risk of mortality after a TAVI procedure. ${ }^{34}$ Therefore, the European Society of Cardiology guidelines for the management of valvular heart disease and the guidelines of the American College of Cardiology (ACC) recommend to use frailty scores to determine a patients' suitability for TAVI. ${ }^{1}{ }^{2}$ Previous studies aimed to identify preoperative factors predictive of postoperative adverse outcomes in older patients undergoing TAVI. ${ }^{34}$ Several predictors of 1-year mortality in older patients have been found, including the presence of frailty, a reduced gait speed and dependence in activities of daily living (ADL). With regard to predictors of short-term outcomes (eg, 30-day mortality), there have been conflicting results, in particular with respect to frailty. ${ }^{5-7}$

The majority of recently created prediction models in older patients focused on the occurrence of long-term mortality. ${ }^{8-10}$ Since the occurrence of postoperative complications results in substantial burden for patients and healthcare systems, it is necessary to focus both on postoperative mortality and morbidity and the overall occurrence of these negative outcomes. ${ }^{112}$

In this study, we aimed to identify predictors of postoperative adverse events, including mortality, hospital readmissions, major postoperative complications and the composite of these outcomes in older patients undergoing TAVI.

\section{METHODS}

\section{Study design and population}

This prospective, single-centre cohort study was conducted at the University Medical Centre Utrecht, a tertiary hospital in the Netherlands. All consecutive patients who visited the geriatric outpatient clinic for a geriatric assessment prior to TAVI between January 2014 and June 2020 were included. Patients were excluded if (a) they were referred for a preoperative geriatric assessment prior to another operation than TAVI, (b) the TAVI operation was cancelled or (c) the 3-month follow-up appointment was planned after 30 June 2020. Data were collected from patients' electronic medical records during the outpatient clinic visit prior to TAVI, during the TAVI admission and 3 months post-TAVI.

\section{TAVI-procedure}

A multidisciplinary heart team consisting of at least one interventional cardiologist and one cardiac surgeon evaluated the patients' suitability for a TAVI-procedure according to current guidelines. A preoperative complete cardiac assessment was performed. The preferred access site was the transfemoral artery. Procedures were performed under local or general anaesthesia. After the TAVI procedure, patients had to take 6 hours bed rest.

\section{Preoperative geriatric assessment}

The preoperative geriatric assessment was performed by a geriatric nurse practitioner under supervision of a geriatrician and involved a Comprehensive Geriatric Assessment (CGA) in which the following domains were assessed: somatic, psychological, social and functional. An anamnesis was performed and data were collected on medical history, medication use (in particular the presence of (hyper) polypharmacy), smoking status, alcohol use, living situation, dependence in (instrumental) activities of daily living ((i)ADL), nutritional status, the presence of a fall in the previous 6 months and the presence of a delirium in the past. With regard to the medical history, the Charlson Comorbidity Index (CCI) score was calculated. ${ }^{13}$ An adjusted CCI score without scoring points for age-category was used. A cut-off value of $\geq 3$ was defined as multimorbidity. Polypharmacy was defined as the use of five or more medications, excluding food supplements without prescription, medication only taken when necessary, dermal creams and eye drops. Hyperpolypharmacy was defined as the use of 10 or more medications. With regard to alcohol use and smoking status, patients scored positive if they were current users, regardless of the amount. Patients lived dependent when they lived in a skilled nursing or assisted nursing facility. Patients lived independent when they lived in their own house, with or without homecare. To assess dependence in (i)ADL the KATZ-15 questionnaire was conducted. ${ }^{14}$ Dependence in (i) ADL was defined as a KATZ-15 score $\geq 2$. The nutritional status was assessed using the Malnutrition Universal Screening Tool (MUST). ${ }^{15}$ Malnutrition was suspected when the MUST score was $\geq 1$. In addition, the American Society of Anaesthesiologists score, determined by an anaesthesiologist, was obtained from the patients' electronic medical records. ${ }^{16}$

Furthermore, a psychical examination was performed, which consisted of measurement of vital signs, gait speed and handgrip strength and a neurological-and functional examination. A decreased gait speed was defined as a gait speed of $\leq 0.80 \mathrm{~m} / \mathrm{s}$ and a decreased handgrip strength was defined as $\leq 20 \mathrm{~kg}$ for women and $\leq 30 \mathrm{~kg}$ for men. ${ }^{17}$ In addition, a Mini-Mental State Examination (MMSE) or Montreal Cognitive Assessment ( $<5 \%$ of the cases, MoCA) was conducted to assess cognitive function. $^{18} 19$ An MMSE score $\leq 24$ or MoCA score $<26$ was indicative for cognitive impairment. To assess the possible presence of a depression, the Geriatric Depression Scale (GDS) questionnaire was conducted. A GDS-15 score $\geq 6$ was suggestive of a depression. ${ }^{20}$

Frailty was assessed according to the Groningen Frailty Indicator (GFI). ${ }^{21}$ This is an internationally applied, validated frailty instrument which offers a multidomain view on the degree of frailty. The GFI questionnaire consists of 15 questions, covering all domains of the CGA. Frailty was present in case of a GFI score of $\geq 4$. Due to varying 
standard instruments to determine frailty in recent years, the GFI score was not reported in all patients by the geriatric nurse practitioner. In these cases, the GFI score was determined by the authors based on information collected during the preoperative geriatric assessment. A few questions of the GFI could not be filled in retrospectively. Therefore, the answers to these questions were rated as missing and the total GFI score was calculated, excluding these questions. Based on the results of the CGA, advice was provided on perioperative delirium prevention including both non-pharmacological interventions and pharmacological interventions if indicated. Furthermore, advice was provided concerning fall-prevention, medication management, mobility, optimising nutritional status and reducing alcohol use and smoking. In some cases, it was recommended to cancel or postpone the TAVI procedure, for example, in case of multimorbidity or severe functional or cognitive impairment. Nonetheless, the cardiologist made the ultimate decision.

\section{Postoperative geriatric involvement}

One day after the TAVI procedure, a geriatric nurse practitioner visited the patient on the cardiac ward to assist in the prevention or treatment of complications prevalent in the geriatric population (eg, falls, delirium, stroke). Nurses from the cardiac ward observed the patients during the hospital stay and in case a postoperative delirium was suspected, the Delirium Observation Screening Scale (DOSS) was assessed three times a day. The DOSS is an early recognition tool for delirium, based on observations by nurses. A score of three and higher indicates a delirium. ${ }^{22}$ A postoperative delirium was confirmed by the geriatric consulting team, based on criteria of the Diagnostic and Statistical Manual of Mental Disorders, Fifth Edition. ${ }^{23}$ A postoperative delirium was treated by non-pharmacological interventions and if indicated, by pharmacological treatment like haloperidol.

\section{Follow-up}

Three months after the TAVI procedure there was a follow-up appointment with a geriatric nurse practitioner, mostly by phone. Patients were asked about their general well-being and physical complaints compared with the situation before the procedure. Data were collected on the occurrence of postoperative complications. Patients were also followed by their cardiologist 6 and 12 months after TAVI.

\section{Outcomes}

The outcomes were mortality and hospital readmissions within 3 months of TAVI and major postoperative complications during hospitalisation according to the ClavienDindo classification (online supplemental table 1). ${ }^{2425}$ The Clavien-Dindo classification was already successfully implemented as outcome classification method in other surgical specialties (eg, non-cardiac thoracic surgery, colorectal surgery and urological surgery $)^{26-30}$ and a recent study proved that this classification adequately measures the quantity and severity of postoperative complications in adult cardiac surgery. ${ }^{31}$ The ClavienDindo classification consists of five categories, each category represents the type of therapy which was required to correct the complication. The need for pharmacological treatment is reflected in category I and II. Category IIIIV range from a complication requiring a surgical, endoscopic or radiological intervention to a life-threatening complication requiring intensive care (unit) management. For example, an arrhythmia requiring the placement of a pacemaker is a Clavien-Dindo grade III complication. Category V reflects the death of a patient. ${ }^{24}{ }^{25}$ A composite outcome was created in which the three outcomes were combined. A Clavien-Dindo grade of II and higher was considered a major postoperative complication. When a patient suffered from two or more complications in different grade categories, the highest grade was used in the analysis.

\section{Statistical analysis}

The prevalence of dichotomised baseline variables is presented as numbers and corresponding percentages. Continuous baseline variables are expressed as mean and SD. In case there were more than $10 \%$ missing values for a variable (which holds for the GDS), the Little's MCAR test was performed to determine whether missing values were completely at random or not. Since the results of the Little's MCAR test showed no significance $(p>0.05)$, multiple imputation methods were not indicated. Univariate logistic regression analyses were performed to identify potential predictors of the outcomes and the composite outcome. Before entering continuous variables into the univariate logistic regression analysis, we first performed the Box-Tidwell procedure to assess whether the continuous variables were linearly related to the logit of the dependent variable.

All variables with $p$ value $\leq 0.10$ in univariate analyses were entered into a stepwise multivariate analysis. ORs with a 95\% CI were calculated. Analyses were performed using IBM Statistical Package for the Social Sciences, V.25 (SPSS).

\section{RESULTS}

\section{Patient inclusion and baseline characteristics}

A total of 555 patients visited the geriatric outpatient clinic for a preoperative geriatric assessment between January 2014 and June 2020. 65 patients were excluded from this study. Reasons for exclusion were referral to the geriatric outpatient clinic because of a preoperative assessment for an intervention other than TAVI $(n=31)$, no 3-month follow-up data available because the follow-up appointment was scheduled after 30 June $2020 \quad(n=20)$, insufficient information collected during preoperative assessment $(\mathrm{n}=10)$ and cancellation of the TAVI procedure $(n=4)$. Operations were mostly cancelled due to 


\begin{tabular}{|c|c|c|c|}
\hline & & $\mathbf{N}$ & $\%$ \\
\hline All patients & & 490 & \\
\hline \multicolumn{4}{|l|}{ Demographics } \\
\hline \multirow[t]{2}{*}{ Age } & Years (mean $\pm S D)$ & $80.7 \pm 6.2$ & \\
\hline & Age $\geq 80$ years & 319 & 65.1 \\
\hline Sex & Male & 232 & 47.3 \\
\hline \multirow[t]{2}{*}{ Smoking } & Current smoker & 31 & 6.3 \\
\hline & Ex-smoker & 198 & 40.4 \\
\hline Alcohol use & Current alcohol user & 241 & 49.2 \\
\hline \multicolumn{4}{|l|}{ Frailty } \\
\hline $\mathrm{GFI}^{*}$ & $\geq 4$ & 170 & 34.7 \\
\hline \multicolumn{4}{|l|}{ Somatic status } \\
\hline ASA class $†$ & $\geq 3$ & 456 & 93.1 \\
\hline CClł‡ & $\geq 3 \S$ & 258 & 52.7 \\
\hline \multirow[t]{3}{*}{ Medication use } & Number (mean $\pm S D)$ & $8.4 \pm 4.5$ & \\
\hline & $\begin{array}{l}\text { Polypharmacy ( } \geq 5 \\
\text { medications) }\end{array}$ & 408 & 83.3 \\
\hline & $\begin{array}{l}\text { Hyperpolypharmacy ( } \geq 10 \\
\text { medications) }\end{array}$ & 163 & 33.3 \\
\hline \multicolumn{4}{|l|}{$\begin{array}{l}\text { Cognitive and } \\
\text { psychological status }\end{array}$} \\
\hline \multirow[t]{2}{*}{ MMSEๆף } & $($ Mean $\pm S D)$ & $27.5 \pm 2.5$ & \\
\hline & MMSE $\leq 24$ & 47 & 9.6 \\
\hline \multirow[t]{2}{*}{ MoCAףा } & $($ Mean $\pm S D)$ & $26 \pm 3.4$ & \\
\hline & $\mathrm{MoCA}<26$ & 8 & 1.6 \\
\hline Impaired cognition & MMSE $\leq 24$ or $\mathrm{MoCA}<26$ & 55 & 11.2 \\
\hline $\mathrm{GDS}^{*}$ & $\geq 6$ & 17 & 3.5 \\
\hline Delirium & In past & 48 & 9.8 \\
\hline \multicolumn{4}{|l|}{ Social status } \\
\hline Living situation & Dependent & 22 & 4.5 \\
\hline \multicolumn{4}{|l|}{ Functional status } \\
\hline Dependence in $\mathrm{ADL}^{\star \star}$ & KATZ6 $\geq 1$ & 114 & 23.3 \\
\hline Dependence in iADL†† & KATZ9 $\geq 1$ & 287 & 60.5 \\
\hline Dependence in (i)ADL ${ }^{*}$ & KATZ15 $\geq 2$ & 225 & 45.9 \\
\hline (At risk of) malnutrition ${ }^{\star *}$ & MUST $\geq 1$ & 75 & 15.3 \\
\hline Gait speed & $<0.8 \mathrm{~m} / \mathrm{s}$ & 98 & 20 \\
\hline Handgrip strength & $\leq 20 \mathrm{~kg}$ female $/ \leq 30 \mathrm{~kg}$ male & 246 & 50.2 \\
\hline Falls & $\geq 1$ in previous 6 months & 93 & 19.1 \\
\hline
\end{tabular}

*Score range from 0 to 15.

†Score range from 1 to 5 .

$\ddagger$ Score range from 0 to 24 .

§Points for age category not included.

IScore range from 0 to 30 .

** Score range from 0 to 6 .

††Score range from 0 to 9 .

ASA, American Society of Anaesthesiologists; $\mathrm{CCl}$, Charlson Comorbidity Index; GDS, Geriatric Depression Scale; GFI, Groningen Frailty Indicator; (i)ADL, (instrumental) activities of daily living; MMSE, mini-mental state examination; MoCA, Montreal Cognitive Assessment; MUST, Malnutrition Universal Screening Tool.

severe comorbidities. Finally, 490 patients were included in the study.

The baseline characteristics of the study population are outlined in table 1 . Mean age was $80.7 \pm 6.2$ years. Five per cent were between the age of 50 and 70 and

\begin{tabular}{|lrc|}
\hline Table 2 Occurrence of outcome measures & & \\
\hline & N & $\%$ \\
\hline Mortality within 3 months of TAVI & 19 & 3.9 \\
\hline Hospital readmission within 3 months of TAVI & 46 & 9.4 \\
\hline Complications according to Clavien-Dindo during admission & 177 & 36.1 \\
\hline Clavien-Dindo grade I & 144 & 29.4 \\
\hline Clavien-Dindo grade II & 69 & 14.1 \\
\hline Clavien-Dindo grade Illa & 66 & 13.5 \\
\hline Clavien-Dindo grade IIIb & 15 & 3.1 \\
\hline Clavien-Dindo grade IVa & 14 & 2.9 \\
\hline Clavien-Dindo grade IVb & 2 & 0.4 \\
\hline Clavien-Dindo grade V & 12 & 2.4 \\
\hline Composite outcome* & 193 & 39.4 \\
\hline
\end{tabular}

*Including mortality and hospital readmission within 3 months of TAVI and the occurrence of major postoperative complications (Clavien-Dindo grade $>$ Il) during hospitalisation.

TAVI, transcatheter aortic valve implantation.

$28 \% 85$ years or older. Two hundred and thirty-two patients $(47.3 \%)$ were male. A total of 170 patients $(34.7 \%)$ were frail. The mean logistic EuroSCORE was $14.8 \%$.

Mortality and hospital readmissions within 3 months of TAVI

Occurrence of outcome measures is displayed in table 2. Twelve patients $(2.4 \%)$ died during hospital admission and 19 patients $(3.9 \%)$ died within 3 months of TAVI. In total, there were 46 readmissions $(9.4 \%)$, of which 22 $(48 \%)$ were cardiac, $23(50 \%)$ non-cardiac and for one readmission $(2 \%)$ the reason could not be traced in the patient file. Cardiac reasons for readmission were often arrhythmias requiring pacemaker implantation or acute decompensated heart failure. Non-cardiac reasons were among others infections (requiring intravenous antibiotics) or cerebrovascular events. Due to the limited number of outcome events within 3 months of TAVI, logistic regression analyses to identify independent predictors were not feasible.

\section{Occurrence of major postoperative complications during hospitalisation}

A total of 177 (36.1\%) patients experienced one or more major postoperative complications (ClavienDindo grade $\geq$ II) during hospital admission. Results of the univariate and multivariate analyses are displayed in table 3. Univariate analysis showed that cognitive impairment (OR 2.30; 95\% CI 1.30 to 4.07), dependence in (i) ADL (OR 1.57; 95\% CI 1.08 to 2.30) and a decreased gait speed (OR 1.64; $95 \%$ CI 1.04 to 2.60) were significantly associated with a higher risk of a major postoperative complication during hospitalisation. Multivariate analysis showed that cognitive impairment was independently associated with a higher risk of a major postoperative complication during hospital admission (OR 2.16; $95 \%$ CI 1.14 to 4.19 ). 
Interventional cardiology

\begin{tabular}{|c|c|c|c|c|}
\hline Demographics & $\begin{array}{l}\text { Univariate } \\
\text { OR }(95 \% \mathrm{Cl})\end{array}$ & $P$ value & $\begin{array}{l}\text { Multivariate } \\
\text { OR }(95 \% \mathrm{Cl})\end{array}$ & $P$ value \\
\hline Age & 1.00 (0.97 to 1.03$)$ & 0.91 & & \\
\hline Sex (male) & 1.37 (0.94 to 1.98$)$ & 0.10 & 0.91 (0.59 to 1.40$)$ & 0.66 \\
\hline Current smoker & 1.12 (0.53 to 2.37 ) & 0.76 & & \\
\hline Alcohol user & $0.62(0.42$ to 0.89$)$ & 0.01 & 0.78 (0.50 to 1.21$)$ & 0.26 \\
\hline \multicolumn{5}{|l|}{ Frailty } \\
\hline $\mathrm{GFI} \geq 4 \S$ & 1.43 (0.96 to 2.13$)$ & 0.08 & 0.73 (0.42 to 1.24$)$ & 0.24 \\
\hline \multicolumn{5}{|l|}{ Somatic status } \\
\hline ASA class $\geq 39$ & 0.91 (0.44 to 1.86$)$ & 0.79 & & \\
\hline $\mathrm{CCl} \geq 3 \dagger^{\star \star \star}$ & 1.37 (0.94 to 1.98$)$ & 0.10 & $1.22(0.80$ to 1.87$)$ & 0.35 \\
\hline Polypharmacy & 1.11 (0.67 to 1.83$)$ & 0.68 & & \\
\hline Hyperpolypharmacy & 1.27 (0.86 to 1.88$)$ & 0.22 & & \\
\hline \multicolumn{5}{|l|}{ Cognitive and psychological status } \\
\hline MMSE $\leq 24$ or MoCA $<26+†$ & 2.30 (1.30 to 4.07$)$ & $<0.01$ & 2.16 (1.14 to 4.19$)$ & 0.02 \\
\hline $\mathrm{GDS} \geq 6 \S$ & 0.57 (0.18 to 1.77$)$ & 0.33 & & \\
\hline Delirium in past & 1.06 (0.57 to 1.96$)$ & 0.85 & & \\
\hline \multicolumn{5}{|l|}{ Social status } \\
\hline Living dependent & 2.20 (0.93 to 5.21$)$ & 0.07 & 1.59 (0.60 to 4.23$)$ & 0.35 \\
\hline \multicolumn{5}{|l|}{ Functional status } \\
\hline Katz15 $\geq 2 \S$ & 1.57 (1.08 to 2.30$)$ & 0.02 & 1.20 (0.73 to 1.97$)$ & 0.47 \\
\hline MUST $\geq 1$ 㧊 & 1.06 (0.64 to 1.77$)$ & 0.81 & & \\
\hline Gait speed $<0.8 \mathrm{~m} / \mathrm{s}$ & 1.64 (1.04 to 2.60$)$ & 0.03 & 1.47 (0.85 to 2.55$)$ & 0.17 \\
\hline Handgrip strength $\leq 20 \mathrm{~kg} / \leq 30 \mathrm{~kg} \ddagger$ & 1.00 (0.68 to 1.47$)$ & $>0.99$ & & \\
\hline Falls in previous 6 months & 1.37 (0.86 to 2.17$)$ & 0.18 & & \\
\hline
\end{tabular}

${ }^{*}$ Clavien-Dindo grade $\geq I I$.

†Points for age category not included.

$\ddagger \leq 20 \mathrm{~kg}$ female $/ \leq 30 \mathrm{~kg}$ male.

§score range from 0 to 15.

IScore range from 1 to 5 .

** Score range from 0 to 24 .

t†Score range from 0 to 30

$\ddagger \ddagger$ Score range from 0 to 6 .

ASA, American Society of Anaesthesiologists; CCI, Charlson Comorbidity Index; GDS, Geriatric Depression Scale; GFI, Groningen Frailty Indicator; MMSE, minimental state examination; MoCA, Montreal Cognitive Assessment; MUST, Malnutrition Universal Screening Tool.

\section{Composite outcome of adverse events}

A total of 193 (39.4\%) patients experienced the composite outcome consisting of mortality or hospital readmission within 3 months of TAVI and occurrence of major postoperative complications (Clavien-Dindo grade $\geq$ II) during hospitalisation. Results from the univariate and multivariate analyses of the composite outcome are presented in table 4. Cognitive impairment was statistically significant associated with an increased risk of the composite outcome in both univariate (OR 2.56; 95\% CI 1.41 to 4.65 ) and multivariate analysis (OR 2.40; 95\% CI 1.21 to 4.79). Univariate analysis showed that current alcohol use was associated with a lower risk (OR 0.62; 95\% CI 0.43 to 0.90 ) and living dependently (OR 2.49; $95 \%$ CI 1.01 to 6.13), dependence in (i) ADL (OR 1.74; 95\% CI 1.20 to 2.54) and a decreased gait speed (OR 1.62; $95 \%$ CI 1.02 to 2.56) with a higher risk of the composite outcome. In the multivariate analysis, these factors were not identified as independent predictors of the composite outcome.

\section{DISCUSSION}

The aim of this study was to identify predictors of postoperative adverse outcomes in older patients undergoing TAVI. Cognitive impairment was identified as an independent predictor of major postoperative complications during hospitalisation and the composite outcome of major complications, hospital readmissions and mortality. No association was found between the other variables and the composite and separate outcomes.

The finding of cognitive impairment as an independent predictor of worse outcomes in older patients is in line with previous studies conducted in patients undergoing TAVI. Yanagisawa $e t$ al evaluated if the presence of preoperative cognitive impairment was associated with postoperative adverse outcomes, in particular 1-year cumulative mortality. ${ }^{32}$ They included TAVI patients aged 70 or higher, whose cognitive performance was assessed using the MMSE. They found that patients with cognitive impairment had more in-hospital adverse outcomes (major bleeding, vascular complications, 


\begin{tabular}{|c|c|c|c|c|}
\hline $\begin{array}{l}\text { Composite outcome: postoperative adverse } \\
\text { events }\end{array}$ & $\begin{array}{l}\text { Univariate } \\
\text { OR }(95 \% \mathrm{Cl})\end{array}$ & $P$ value & $\begin{array}{l}\text { Multivariate } \\
\text { OR }(95 \% \mathrm{Cl})\end{array}$ & $P$ value \\
\hline \multicolumn{5}{|l|}{ Demographics } \\
\hline Age & 1.01 (0.98 to 1.04$)$ & 0.51 & & \\
\hline Sex (male) & $0.87(0.60$ to 1.25$)$ & 0.45 & & \\
\hline Current smoker & 1.13 (0.54 to 2.38$)$ & 0.75 & & \\
\hline Alcohol user & $0.62(0.43$ to 0.90$)$ & 0.01 & 0.77 (0.50 to 1.19$)$ & 0.23 \\
\hline \multicolumn{5}{|l|}{ Frailty } \\
\hline $\mathrm{GFI} \geq 4^{* *}$ & 1.47 (0.99 to 2.19$)$ & 0.06 & 0.67 (0.39 to 1.15$)$ & 0.14 \\
\hline \multicolumn{5}{|l|}{ Somatic status } \\
\hline ASA class $\geq 3^{*}$ & 1.11 (0.54 to 2.27$)$ & 0.78 & & \\
\hline $\mathrm{CCl} \geq 3 \dagger \ddagger$ & 1.38 (0.96 to 2.00$)$ & 0.09 & 1.23 (0.81 to 1.86$)$ & 0.34 \\
\hline Polypharmacy & 1.18 (0.72 to 1.95$)$ & 0.52 & & \\
\hline Hyperpolypharmacy & 1.27 (0.86 to 1.87$)$ & 0.23 & & \\
\hline \multicolumn{5}{|l|}{ Cognitive and psychological status } \\
\hline MMSE $\leq 24$ or MoCA $<26 \S$ & 2.56 (1.41 to 4.65$)$ & $<0.01$ & 2.40 (1.21 to 4.79$)$ & 0.01 \\
\hline GDS $\geq 6^{* *}$ & 0.46 (0.15 to 1.45$)$ & 0.19 & & \\
\hline Delirium in past & 1.20 (0.66 to 2.21$)$ & 0.55 & & \\
\hline \multicolumn{5}{|l|}{ Social status } \\
\hline Living dependent & 2.49 (1.01 to 6.13$)$ & 0.05 & 1.85 (0.66 to 5.19$)$ & 0.24 \\
\hline \multicolumn{5}{|l|}{ Functional status } \\
\hline Katz15 $\geq 2^{\star \star}$ & 1.74 (1.20 to 2.54$)$ & $<0.01$ & 1.42 (0.87 to 2.31$)$ & 0.16 \\
\hline MUST $\geq 1 \rrbracket$ & $1.03(0.62$ to 1.71$)$ & 0.90 & & \\
\hline Gait speed $<0.8 \mathrm{~m} / \mathrm{s}$ & 1.62 (1.02 to 2.56$)$ & 0.04 & 1.32 (0.76 to 2.28$)$ & 0.32 \\
\hline Handgrip strength $\leq 20 \mathrm{~kg} / \leq 30 \mathrm{kgt \dagger}$ & 1.11 (0.76 to 1.63$)$ & 0.58 & & \\
\hline Falls in previous 6 months & 1.39 (0.88 to 2.19$)$ & 0.16 & & \\
\hline
\end{tabular}

*Score range from 1 to 5 .

†Points for age category not included.

$\ddagger$ Score from range 0 to 24 .

§Score range from 0 to 30 .

IScore range from 0 to 6 .

** Score range from 0 to 15 .

††20 kg female/ $\leq 30 \mathrm{~kg}$ male.

ASA, American Society of Anaesthesiologists; CCI, Charlson Comorbidity Index; GDS, Geriatric Depression Scale; GFI, Groningen Frailty Indicator; MMSE, mini-mental state examination; MoCA, Montreal Cognitive Assessment; MUST, Malnutrition Universal Screening Tool.

acute kidney injury, prolonged hospital stay) and that cognitive impairment was an independent predictor of 1-year allcause mortality. ${ }^{32}$

Khan et al included TAVI patients who were screened on the presence of geriatric risk factors. ${ }^{33}$ They found that the presence of cognitive deficits (according to the Mini-Cog test) was associated with the occurrence of a postoperative delirium and 30-day mortality. ${ }^{33}$

A possible explanation for this finding could be that patients with cognitive impairment are more prone to develop a postoperative delirium and that this is reflected in our outcome 'major postoperative complications during hospitalisation according to the Clavien-Dindo classification' and the composite outcome. However, only a minority (11.3\%) of all patients with a ClavienDindo grade II complication experienced a delirium for which pharmacological treatment was necessary. Another explanation, as stated by Yanagisawa $e t$ al, could be that a part of the patients with cognitive deficits are known to suffer from vascular cognitive impairment caused by systemic vascular risk factors. ${ }^{32}$ The presence of these vascular risk factors might explain the increased risk of postoperative morbidity in patients with cognitive impairment. In contrast to previous studies conducted in TAVI patients, ${ }^{34}$ we did not find an association between other variables, like frailty, and postoperative adverse outcomes. A possible explanation for this finding could be that all TAVI patients included in our study had a 
preoperative CGA. Based on the results of the CGA, an extensive advice was given with regard to identified risk factors. Therefore, our study population differs from the study population in previous studies, since all patients in our study had a preoperative intervention consisting of a CGA and the subsequent advice for appropriate treatment to prevent/reduce postoperative adverse outcomes.

This study has several strengths. The study design was prospective and a relatively large number of patients was included. Whereas previous studies mostly focused on separate outcomes, in particular mortality, this study also assessed a composite outcome, including mortality and hospital readmission within 3 months of TAVI and the occurrence of major postoperative complications during hospitalisation, assessing both postoperative mortality and morbidity. Therefore, an advantage of this composite outcome is that it reflects the overall course following TAVI. Furthermore, we included a wide variety of potential preoperative predictive factors, covering all the different domains of the CGA. In this study, frailty was assessed by a validated frailty instrument that includes all domains of the CGA and therefore it offers a broad assessment of frailty in comparison to other frailty instruments that cover less domains of the CGA. ${ }^{21}$

This study has some limitations. Due to the limited number of events for mortality and hospital readmission within 3 months of TAVI, planned logistic regression analyses were not feasible. Furthermore, during the study period, the local guidelines regarding frailty instruments were changing. Therefore, for a number of patients, the GFI score was not reported by the geriatric nurse practitioner and had to be calculated by the authors. However, some questions of the GFI are subjective and could not be filled in retrospectively. The answers for these questions were rated as missing, and the total GFI score was calculated, excluding these questions. This might have resulted in an underestimation of the number of frail patients. However, the frailty prevalence in this study corresponded to the prevalence range $(29 \%-63 \%)$ of frailty in patients undergoing TAVI that was found in a recent meta-analysis. ${ }^{34}$ Finally, during the 3-month follow-up appointment with the geriatric nurse practitioner, patients were often not explicitly asked if they had been readmitted to a hospital within 3 months of TAVI. This may lead to an underestimation of the number of participants with a readmission if a patient was admitted to a hospital other than the University Medical Centre Utrecht.

\section{Clinical implications}

The results of this study have some important clinical implications. We found cognitive impairment to be independently associated with a higher risk of postoperative adverse events. Screening for cognitive impairment with a screening tool like the MMSE or MoCA could help identify patients who are at increased risk of unfavourable outcomes and will provide additional information on the potential risks of TAVI, which improves shared-decision making. Therefore, we advise to include screening for cognitive impairment in the current local and international guidelines. ${ }^{1}$ The 2017 ACC expert consensus on a decision pathway for TAVI in the management of adults with aortic stenosis, is innovative by advising to assess cognition by means of the MMSE, however, cognitive function is not yet included in their four proposed risk categories. ${ }^{2}$ In addition, if a patient is suspected of cognitive decline or impairment after screening for cognitive impairment, he or she could be monitored more closely during admission and afterwards, especially by a geriatric team in order to detect and anticipate on problems in an early stage.

\section{CONCLUSION}

This study identified cognitive impairment as an independent predictor of postoperative adverse events in older patients undergoing TAVI. Therefore, it is important to screen for cognitive impairment prior to TAVI, as this can identify patients who are at increased risk to develop a postoperative adverse event. It is recommended to include screening for cognitive impairment in current TAVI guidelines.

Contributors Study concept and design: ME-V, HLK. Acquisition of data: JEMP, MA. Analysis and interpretation of data: LD, JEMP, PRS, HLK. Drafting of the manuscript: LD, JEMP. Critical revision of the manuscript: PRS, ME-V, MA, HLK. All authors critically reviewed and approved the final manuscript.

Funding The authors have not declared a specific grant for this research from any funding agency in the public, commercial or not-for-profit sectors.

Competing interests None declared.

Patient consent for publication Not required.

Ethics approval The study involved data obtained from usual care and the local Ethics Committee of the University Medical Centre Utrecht confirmed that this study did not fall under the scope of The Medical Research Involving Human Subjects Act. Therefore, patient consent was not required.

Provenance and peer review Not commissioned; externally peer reviewed.

Data availability statement Data are available upon reasonable request. The datasets used and/or analysed during the current study are available from the corresponding author on reasonable request.

Open access This is an open access article distributed in accordance with the Creative Commons Attribution Non Commercial (CC BY-NC 4.0) license, which permits others to distribute, remix, adapt, build upon this work non-commercially, and license their derivative works on different terms, provided the original work is properly cited, appropriate credit is given, any changes made indicated, and the use is non-commercial. See: http://creativecommons.org/licenses/by-nc/4.0/.

ORCID iD

Judith E M Pals http://orcid.org/0000-0001-5173-1733

\section{REFERENCES}

1 Falk V, Baumgartner H, Bax JJ, et al. 2017 ESC/EACTS guidelines for the management of valvular heart disease. Eur $J$ cardio-thoracic Surg 2017;52:616-64.

2 Otto CM, Kumbhani DJ, Alexander KP, et al. 2017 ACC expert consensus decision pathway for transcatheter aortic valve replacement in the management of adults with aortic stenosis: a report of the American college of cardiology task force on clinical expert consensus documents. J Am Coll Cardiol 2017;69:1313-46.

3 Anand A, Harley C, Visvanathan A, et al. The relationship between preoperative frailty and outcomes following transcatheter aortic valve implantation: a systematic review and meta-analysis. Eur Heart J Qual Care Clin Outcomes 2017;3:123-32.

4 van Mourik MS, Velu JF, Lanting VR, et al. Preoperative frailty parameters as predictors for outcomes after transcatheter aortic valve implantation: a systematic review and meta-analysis. Neth Heart J 2020;28:280-92

5 Green P, Arnold SV, Cohen DJ, et al. Relation of frailty to outcomes after transcatheter aortic valve replacement (from the partner trial). Am J Cardiol 2015;116:264-9. 
6 Green P, Woglom AE, Genereux P, et al. The impact of frailty status on survival after transcatheter aortic valve replacement in older adults with severe aortic stenosis: a single-center experience. JACC Cardiovasc Interv 2012;5:974-81.

7 Assmann P, Kievit P, van der Wulp K, et al. Frailty is associated with delirium and mortality after transcatheter aortic valve implantation. Open Heart 2016;3:e000478.

8 Skaar E, Eide LSP, Norekvål TM, et al. A novel geriatric assessment frailty score predicts 2-year mortality after transcatheter aortic valve implantation. Eur Hear J - Qual Care Clin Outcomes 2019;5:153-60.

9 Goudzwaard JA, de Ronde-Tillmans MJAG, El Faquir N, et al. The erasmus frailty score is associated with delirium and 1-year mortality after transcatheter aortic valve implantation in older patients. the tavi care \& cure program. Int J Cardiol 2019;276:48-52.

10 Rogers T, Alraies MC, Moussa Pacha $\mathrm{H}$, et al. Clinical frailty as an outcome predictor after transcatheter aortic valve implantation. Am J Cardiol 2018;121:850-5.

11 Sieber FE, Barnett SR. Preventing postoperative complications in the elderly. Anesthesiol Clin 2011;29:83-97.

12 Karakoc D. Surgery of the elderly patient. Int Surg 2016:101:161-6.

13 Charlson ME, Pompei P, Ales KL, et al. A new method of classifying prognostic comorbidity in longitudinal studies: development and validation. J Chronic Dis 1987;40:373-83.

14 Laan W, Zuithoff NPA, Drubbel I, et al. Validity and reliability of the Katz-15 scale to measure unfavorable health outcomes in community-dwelling older people. J Nutr Health Aging 2014;18:848-54.

15 Elia M. Nutritional screening of adults: a multidisciplinary responsibility. development and use of the 'malnutrition universal screening tool' ('must') for adults; 2003: 127.

16 Doyle D, Goyal A, Bansal P. American society of anesthesiologists classification (ASA class). StatPearls Treasure, 2020.

17 Reiss J, Iglseder B, Alzner R, et al. Sarcopenia and osteoporosis are interrelated in geriatric inpatients. $Z$ Gerontol Geriatr 2019;52:688-93.

18 Folstein MF, Folstein SE, McHugh PR. "Mini-mental state": a practical method for grading the cognitive state of patients for the clinician. J Psychiatr Res 1975;12:189-98.

19 Nasreddine ZS, Phillips NA, BÃ@dirian ValÃ@rie, et al. The Montreal cognitive assessment, MoCA: a brief screening tool for mild cognitive impairment. J Am Geriatr Soc 2005;53:695-9.

20 Yesavage JA, Brink TL, Rose TL, et al. Development and validation of a geriatric depression screening scale: a preliminary report. $J$ Psychiatr Res 1982;17:37-49.
21 Stevernik N, Slaets JPL, Schuurmans H. Measuring frailty: development and testing the GFI (Groningen frailty indicator). Gerontologist 2001;41:236-7.

22 Schuurmans MJ, Shortridge-Baggett LM, Duursma SA. The delirium observation screening scale: a screening instrument for delirium. Res Theory Nurs Pract 2003;17:31-50.

23 American Psychiatric Association. Diagnostic and statistical manual of mental disorders. 5 edn, 2013.

24 Dindo D, Demartines N, Clavien P-A. Classification of surgical complications: a new proposal with evaluation in a cohort of 6336 patients and results of a survey. Ann Surg 2004;240:205-13.

25 Clavien PA, Barkun J, de Oliveira ML, et al. The clavien-dindo classification of surgical complications: five-year experience. Ann Surg 2009;250:187-96.

26 Seely AJE, Ivanovic J, Threader J, et al. Systematic classification of morbidity and mortality after thoracic surgery. Ann Thorac Surg 2010;90:936-42.

27 Bosma E, Pullens MJJ, de Vries J, et al. The impact of complications on quality of life following colorectal surgery: a prospective cohort study to evaluate the Clavien-Dindo classification system. Colorectal Dis 2016;18:594-602.

28 Geskin AA, Westney OL, Graber WJ, et al. Complications of perioperative ureteral catheter placement: experience at a major cancer center. Urology 2021:S0090-4295.

29 Wakita N, Hinata N, Suzuki K. Comparison of robot-assisted partia nephrectomy for complex (RENAL scores $\geq 10$ ) and non-complex renal tumors : a single-center experience. Int $J$ Urol.

30 Winter R, Haug I, Lebo $\mathrm{P}$, et al. Standardizing the complication rate after breast reduction using the Clavien-Dindo classification. Surgery 2017;161:1430-5.

31 Hébert M, Cartier R, Dagenais F, et al. Standardizing postoperative complications-validating the clavien-dindo complications classification in cardiac surgery. Semin Thorac Cardiovasc Surg 2021:33:443-51.

32 Yanagisawa R, Tanaka M, Yashima F, et al. Frequency and consequences of cognitive Impairmentin patients underwent transcatheter aortic valve implantation. Am J Cardiol 2018;122:844-50.

33 Khan MM, Lanctôt KL, Fremes SE, et al. The value of screening for cognition, depression, and frailty in patients referred for TAVI. Clin Interv Aging 2019;14:841-8.

34 Piankova P, Afilalo J. Prevalence and prognostic implications of frailty in transcatheter aortic valve replacement. Cardiol Clin 2020;38:75-87. 